\title{
Refractory Malignant Soft Tissue Neoplasm
}

National Cancer Institute

\section{Source}

National Cancer Institute. Refractory Malignant Soft Tissue Neoplasm. NCI Thesaurus.

Code C150537.

Malignant soft tissue neoplasm that is resistant to treatment. 